\title{
PERILAKU CARING PERAWAT DAN \\ KEPUASAN PASIEN DI RUMAH SAKIT
}

\author{
Tri Yuli Susanti ${ }^{1)}$, Rista Apriana ${ }^{2)}$ \\ 1 Program Studi S1 Keperawatan Stikes Widya Husada \\ ${ }^{2}$ Program Studi S1 Keperawatan UPN Veteran Jakarta \\ Email : triyulisusanti16@gmail.com
}

\begin{abstract}
ABSTRAK
Latar Belakang : Caring merupakan komponen yang sangat penting dalam keperawatan dan merupakan inti dari praktek keperawatan karena mengandung nilai-nilai humanistik, menghormati kebebasan manusia, menekankan pada peningkatan kemampuan dan kemandirian, peningkatan pengetahuan dan menghargai setiap manusia. Perawat yang mempunyai nilai dan jiwa caring mempunyai perilaku kerja yang sesuai dengan prinsip etik dikarenakan kepedulian perawat yang memandang klien sebagai makhluk humantistik, sehingga termotivasi untuk memberikan pelayanan keperawatan yang bermutu tinggi. Tujuan Penelitian ini adalah untuk mengetahui hubungan perilaku caring perawat dengan kepuasan pasien di rumah sakit. Metode : Jenis penelitian ini merupakan kuantitatif non eksperimen dengan desain cross sectional. Pengambilan sampel dengan tehnik Purposive Sampling. Data dikumpulkan melalui kuesioner, dianalisis menggunakan uji statistik Spearman Rank dengan batas kemaknaan 0,05. Hasil : Terdapat $74,8 \%$ perawat berperilaku caring dan $80,5 \%$ pasien merasa puas dengan hasil uji statistik nilai $\mathrm{p}$ value $0,039 \leq \alpha=0,05 \mathrm{r}=(0,187)$. Kesimpulan : Hasil penelitian menunjukkan bahwa ada hubungan perilaku caring perawat dengan kepuasan pasien
\end{abstract}

Keyword : Caring Perawat, Kepuasan Pasien 


\title{
CARING BEHAVIOR OF NURSES AND \\ PATIENT SATISFACTION IN HOSPITALS
}

\begin{abstract}
Background : Caring is a very important component in nursing and is the core of nursing practice because it contains humanistic values, respects human freedom, emphasizes increasing ability and independence, increasing knowledge and respect for every human being. Nurses who have caring values and souls will have behaviors that are in accordance with ethical principles due to caregivers who view clients as humantistic beings, so they are motivated to provide highquality nursing services. The purpose of the study was to determine the relationship of caring behavior of nurses with patient satisfaction in Dr. RSUD Adhyatma, MPH Semarang. Methods : The research used a kuantitatif non eksperimental with cross sectional design. Sampling techniques is Purposive Sampling. Data were collected through questionnaires, were analyzed using the Spearman Rank statistical test with a significance limit of 0,05. Result : There are $73,8 \%$ of nurses behave in a caring and $80,5 \%$ patient feel satisfied with the statistical test $\mathrm{p}$ value $0,039 \leq \alpha=0,05 \quad r=(0,187)$. Conclution : Result showed that there was correlation between caring behavior of nurses with patient satisfaction
\end{abstract}

Keyword : a nurse caring, patient satisfaction

Alamat korespondensi : Fikkes UPN Veteran Jakarta, Jln Limo Raya No 1 Kelurahan Limo, Kecamatan Limo, Depok

Alamat email : $\quad$ ristaapriana@upnvj.ac.id

Nomor Hp $\quad$ :1. 082141005762

2. 085742228244 (WA) 


\section{PENDAHULUAN}

Kepuasan pelanggan (pasien) adalah perasaan senang atau puas bahwa produk atau jasa yang diterima telah sesuai atau melebihi harapan pelanggan. Kepuasan pasien merupakan salah satu indikator kualitas pelayanan yang kita berikan dan kepuasan pasien adalah suatu modal untuk mendapatkan pasien lebih banyak lagi dan untuk mendapatkan pasien yang loyal (setia). Pasien yang loyal akan menggunakan kembali pelayanan kesehatan yang sama bila mereka membutuhkan lagi, bahkan telah diketahui bahwa pasien yang loyal akan mengajak orang lain untuk menggunakan fasilitas pelayanan kesehatan yang sama. Kepuasan pasien terjadi apabila apa yang menjadi kebutuhan, keinginan, harapan pasien dapat terpenuhi, maka pasien akan puas. (Nursalam, 2014)

Hasil survey kepuasan yang didapat dari data Rumah Sakit Cahya Kawaluyan Jawa Barat pada bulan Januari 2013 menyatakan 52\% kurang puas terhadap pelayanan keperawatan di bagian unit gawat darurat, kemudian 27\% diantaranya tidak puas dengan kecepatan dan ketepatan perawat dalam memberikan asuhan keperawatan kepada pasien, $18 \%$ tidak puas dengan informasi yang didapat pasien dari perawat karena perawat juga tidak ramah, $7 \%$ tidak puas dengan waktu tunggu, dan ada 1\% kurang puas karena pasien menunggu lama untuk mendapat pemeriksaan dan kemudian pergi meninggalkan ruang unit gawat darurat.(dalam jurnal Hubungan Perilaku Caring Perawat dengan Kepuasan Pasien False Emergency di Unit Gawat Darurat Rumah Sakit Cahya Kawaluyan. Jawa Barat, 2013)

Beberapa faktor yang mempengaruhi kepuasan pasien, yaitu jenis paket jasa pelayanan kesehatan yang diterima, empati (sikap peduli) dalam hal ini adalah caring perawat karena institusi pelayanan kesehatan dianggap baik apabila dalam memberikan pelayanan lebih memperhatikan kebutuhan pasien, biaya (cost) segi biaya yang dikeluarkan, penampilan fisik (kerapian) petugas kesehatan, kondisi kebersihan dan kenyamanan ruangan (tangibility), jaminan keamanan yang ditunjukkan oleh petugas kesehatan (assurance), keandalan dan keterampilan (realiability) petugas kesehatan merawat pasien, kecepatan petugas menanggapi keluhan pasien (responsiveness) (Muninjaya, 2013). 
Caring merupakan proses interpersonal, dan hubungan antara pemberi asuhan keperawatan dengan penerima asuhan akan menjadi kekuatan perantara yang penting. (Paul Morrison dan Philip Burnard 2009). Caring adalah suatu tindakan yang didasari pada

keprihatinan terhadap masalah orang lain atau kebutuhan orang lain dan memiliki niat dan usaha untuk membantunya (Dedi Mahardi, 2013). Penelitian yang dilakukan oleh Laila (2011) di ruang penyakit dalam RSUD Pariaman Padang mendapatkan hasil bahwa 57\% pasien tidak puas terhadap perilaku caring perawat, sebanyak 66 pasien menilai perilaku caring perawat kurang.

Berdasarkan wawancara dengan 7 pasien yang dilakukan oleh peneliti tanggal 13 Februari 2017 di ruang rawat inap RSUD Dr. Adhyatma Semarang, peneliti melakukan wawancara di ruang alamanda dan anggrek mendapatkan hasil bahwa perawat yang bekerja di ruang alamanda dan anggrek memiliki perilaku tidak caring, seperti perawat jarang memberikan perhatian terhadap pasien, tidak peduli terhadap keadaan pasien (tidak menanyakan obat sudah diminum atau belum, sudah makan atau belum) perawat juga jarang berkomunikasi dengan pasien mengenai penyakit, perawat judes, ketus, tidak memuaskan ketika menjawab pertanyaan dari pasien maupun keluarga pasien. Pasien merasa tidak puas terhadap pelayanan keperawatan. Perawat kurang terampil dalam memberikan asuhan keperawatan kepada pasien, kurang cepat menanggapi panggilan pasien, perawat tidak mengecek keadaan pasien dan hanya datang disaat memberikan tindakan medis.

Mengingat pentingnya perilaku caring sangat diperlukan dalam meningkatkan kepuasan pasien maka peneliti berkeinginan untuk meneliti "Hubungan perilaku caring perawat dengan kepuasan pasien di ruang rawat inap RSUD Dr. Adhyatma, MPH Semarang",

\section{METODE PENELITIAN}

Jenis penelitian yang digunakan adalah penelitian kuantitatif non eksperimen yaitu penelitian yang datanya dinyatakan dalam angka dan dianalisis dengan teknik statistik dan subjeknya tidak dikenai perlakuan atau intervensi terhadap variabel-variabel yang diteliti 
tetapi diukur sifat-sifatnya. Rancangan yang digunakan cross sectional, yaitu jenis penelitian yang dilakukan untuk mendeskripsikan atau menggambarkan suatu fenomena yang terjadi di dalam masyarakat data variabel independen dan dependen hanya satu kali pada satu saat point time approach (Notoadmojo 2012), dimana peneliti melakukan pengukuran variabel independennya yaitu perilaku caring perawat dan juga pengukuran terhadap variabel dependennya yaitu kepuasan pasien pada saat yang bersamaan.

Populasi dari penelitian ini adalah pasien di ruang rawat inap RSUD Dr. Adhyatma MPH Semarang dengan jumlah 178 pasien dan jumlah sampel sebanyak 123 pasien menggunakan rumus slovin dan pengambilan sampel menggunakan purposive sampling yaitu pengambilan sampel berdasarkan pada kriteria tertentu yang sebelumnya ditetapkan oleh peneliti, subjek yang memenuhi kriteria sampel (Santjaka, 2011)

Instrumen yang digunakan dalam penelitian ini adalah kuesioner mengenai Hubungan perilaku caring perawat dengan kepuasan pasien di ruang rawat inap RSUD Dr. Adhyatma, MPH Semarang, yaitu kuesioner perilaku caring perawat terdiri dari 20 pernyataan dan kuesioner kepuasan pasien yang terdiri dari 20 pernyataan.

Pada kuesioner perilaku caring perawat tidak dilakukan uji validitas data karena sudah dilakukan uji validitas oleh peneliti sebelumnya yaitu Setiyoningsih (2014) di ruang ICU RS PKU Muhammadiyah Gombong, begitu pula untuk kuesioner kepuasan pasien juga tidak dilakukan uji validitas data karena sudah dilakukan uji validitas oleh peneliti sebelumnya yaitu Lisa Rahmayanti (2009) di Rumah Sakit Bunda Margonda Depok.

Analisa univariat pada penelitian ini bertujuan untuk menggambarkan karakteristik umum variabel yaitu perilaku caring perawat dan kepuasan pasien dalam bentuk distribusi frekuensi. Analisis bivariat pada penelitian ini, mengetahui hubungan perilaku caring perawat dengan kepuasan pasien. Uji statistik yang digunakan dalam penelitian ini adalah uji Rank Spearman karena data yang diukur adalah data kategorik nonparametrik berupa data ordinal ordinal. 


\section{HASIL PENELITIAN}

\section{A. Karakteristik Responden Berdasarkan Umur}

Tabel 4.1

Distribusi Frekuensi Karakteristik Responden

Berdasarkan Umur Pasien

Bulan Juni 2017

$(\mathrm{n}=123)$

\begin{tabular}{ccc}
\hline Umur & Frekuensi $(\mathbf{n})$ & Presentase $(\%)$ \\
\hline $17-25$ tahun & 13 & $10,6 \%$ \\
$26-35$ tahun & 22 & $17,9 \%$ \\
$36-55$ tahun & 28 & $22,8 \%$ \\
56-65 tahun & 29 & $23,6 \%$ \\
$>$ 65 tahun & 31 & $25,2 \%$ \\
\hline Total & $\mathbf{1 2 3}$ & $\mathbf{1 0 0 , 0 \%}$ \\
\hline
\end{tabular}

\section{B. Karakteristik Responden Berdasarkan Jenis Kelamin}

Tabel 4.2

Distribusi Frekuensi Karakteristik Responden

Berdasarkan Jenis Kelamin Pasien

Bulan Juni 2017

\begin{tabular}{ccc} 
& $(\mathrm{n}=123)$ & \\
\hline Jenis Kelamin & $\begin{array}{c}\text { Frekuensi } \\
(\mathbf{n})\end{array}$ & Presentase (\%) \\
& 59 & 48 \\
Laki-laki & 64 & 52 \\
\hline Perempuan & $\mathbf{1 2 3}$ & $\mathbf{1 0 0 \%}$ \\
\hline Total & &
\end{tabular}

\section{Karakteristik Responden Berdasarkan Pendidikan}

Tabel 4.3

Distribusi Ferkuensi Karakteristik Responden

Berdasarkan Pendidikan Pasien

Bulan Juni 2017

$(\mathrm{n}=123)$

\begin{tabular}{ccc}
\hline Pendidikan & $\begin{array}{c}\text { Frekuensi } \\
(\mathbf{n})\end{array}$ & $\begin{array}{c}\text { Presentase } \\
(\mathbf{\%})\end{array}$ \\
\hline SD & 20 & 16,3 \\
SMP & 49 & 39,8 \\
SMA & 39 & 31,7 \\
Perguruan Tinggi & 15 & 12,2 \\
\hline Total & $\mathbf{1 2 3}$ & $\mathbf{1 0 0 , 0 \%}$ \\
\hline
\end{tabular}




\section{Gambaran perilaku Caring Perawat}

Tabel 4.4

Distribusi Frekuensi Karakteristik Responden Berdasarkan

Perilaku Caring Perawat Terhadap Pasien

Bulan Juni 2017

$$
(\mathrm{n}=123)
$$

\begin{tabular}{cccc}
\hline Perilaku Caring perawat & Frekuensi (n) & Persentase (\%) \\
\hline Caring & 92 & $74,8 \%$ \\
\hline & Tidak caring & 31 & $25,2 \%$ \\
\hline Total & & $\mathbf{1 2 3}$ & $\mathbf{1 0 0 , 0 \%}$ \\
\hline
\end{tabular}

E. Gambaran kepuasan Pasien

Tabel 4.5

Distribusi Frekuensi Karakteristik Responden Berdasarkan Perilaku Caring Perawat Terhadap Pasien

Bulan Juni 2017

\begin{tabular}{ccc}
\multicolumn{2}{c}{$(\mathrm{n}=123)$} \\
\hline Kepuasan & $\begin{array}{c}\text { Frekuensi } \\
(\mathbf{n})\end{array}$ & Persentase (\%) \\
\hline Puas & 99 & $80,5 \%$ \\
\hline Tidak Puas & 24 & $19,5 \%$ \\
\hline Total & $\mathbf{1 2 3}$ & $\mathbf{1 0 0 , 0 \%}$ \\
\hline
\end{tabular}

\section{F. Hubungan perilaku caring perawat dengan kepuasan pasien}

Tabel 4.6

Hubungan Perilaku Caring Perawat dengan Kepuasan Pasien

Bulan Juni 2017

$$
(\mathrm{n}=36)
$$

\begin{tabular}{|c|c|c|c|c|c|c|c|c|}
\hline \multirow{3}{*}{$\begin{array}{l}\text { Perilaku caring } \\
\text { perawat }\end{array}$} & \multicolumn{4}{|c|}{ Kepuasan } & \multicolumn{2}{|c|}{ Total } & \multirow[t]{2}{*}{$r$} & \multirow{3}{*}{$\begin{array}{l}P \\
\text { value }\end{array}$} \\
\hline & \multicolumn{2}{|c|}{ Puas } & \multicolumn{2}{|c|}{ Tidak puas } & \multirow[b]{2}{*}{$\mathrm{N}$} & \multirow[b]{2}{*}{$\%$} & & \\
\hline & $\mathrm{N}$ & $\%$ & $\mathrm{~N}$ & $\%$ & & & \multirow{3}{*}{0,187} & \\
\hline Caring & 78 & $84,8 \%$ & 14 & $15,2 \%$ & 92 & $100 \%$ & & \multirow[t]{2}{*}{0,039} \\
\hline Tidak caring & 21 & $67,7 \%$ & 10 & $32,3 \%$ & 31 & $100 \%$ & & \\
\hline Total & 99 & $80,5 \%$ & 45 & $19,5 \%$ & 123 & $100 \%$ & & \\
\hline
\end{tabular}


Berdasarkan tabel 4.6 menunjukkan bahwa puas dan caring sebesar $84,8 \%$ sedangkan puas dan tidak caring sebesar 67,7\%, dengan demikian dapat disimpulkan bahwa puas dan caring nilainya lebih besar daripada yang puas dan tidak caring, hal ini membuktikan bahwa semakin caring perawat maka pasien akan semakin puas.

Berdasarkan hasil analisis dengan menggunakan uji rank spearman yang dilakukan mengenai hubungan perilaku caring perawat dengan kepuasan pasien di rumah sakit diperoleh nilai $\rho$ value sebesar 0,039 dengan taraf signifikan 0,05, dapat disimpulkan bahwa $\rho$ value $<0,05$ maka Ha diterima dan Ho ditolak yang berarti ada hubungan perilaku caring perawat dengan kepuasan pasien di rumah sakit terdapat kekuatan hubungan nilai $r$ sebesar 0,187, hal ini menunjukkan bahwa terdapat hubungan yang positif sebesar 0,187 (rendah) yaitu berada dalam kekuatan korelasi sangat lemah atau sangat rendah dengan arah kolerasi searah. Nilai positif pada koefisien korelasi $r$ menunjukkan bahwa semakin tinggi nilai perilaku caring perawat maka nilai kepuasan pasien semakin tinggi.

\section{PEMBAHASAN}

\section{Gambaran umur, jenis kelamin dan tingkat pendidikan}

Hasil penelitian menunjukkan bahwa karakteristik responden remaja sebanyak 13 orang (10,6\%), dewasa awal sebanyak 22 orang (17,9\%), dewasa akhir sebanyak 28 orang (22,8\% tahun), lansia sebanyak 29 orang $(23,6 \%)$, dan manula sebanyak 31 orang $(25,2 \%)$. Usia dalam hal ini berkaitan dengan kemampuan mengambil keputusan, lebih bijaksana, lebih mampu berfikir rasional, dan lebih dapat mengendalikan emosi (Siagian 2001 dalam Munawaroh 2011). Responden dalam penelitian ini sebagian besar tergolong usia dewasa dan lansia yang memiliki tingkat kematangan emosi yang hampir sama sehingga persepsi responden terhadap kepuasan pelayanan yang diterima tidak jauh berbeda.

Hasil penelitian didapatkan data bahwa responden dengan jenis kelamin laki-laki 59 orang $(48,0 \%)$ dan berjenis kelamin perempuan 64 orang $(52,0 \%)$. Supriatin (2009) mengemukakan bahwa tidak ada hubungan yang bermakna antara jenis kelamin perempuan dan laki-laki, Pasien laki-laki maupun perempuan memperoleh kepuasan pada hal-hal yang sama sehingga membutuhkan perlakuan yang sama dari perawat. 
Hasil penelitian menunjukkan bahwa karakteristik responden yang berpendidikan SD sebanyak 20 orang (16,3\%), SMP sebanyak 49 orang (39,8\%), SMA sebanyak 39 orang $(31,7 \%)$ dan Perguruan tinggi sebanyak 15 orang (12,2\%). Munawaroh (2011) menyebutkan pendidikan rendah mempengaruhi seseorang dalam bertindak termasuk dalam mencari tempat pelayanan kesehatan. Biasanya pasien tidak mempertimbangkan aspek dari mutu rumah sakit yang dituju, namun pasien lebih mementingkan sakitnya bisa cepat tertolong dan cepat sembuh. Dalam penelitian ini sebagian besar responden pada kategori pendidikan SMA kebawah sehingga persepsi mereka terhadap kepuasan pelayanan kesehatan tidak jauh berbeda.

\section{Gambaran perilaku caring perawat dan kepuasan pasien}

Hasil penelitian yang dilakukan oleh peneliti menunjukkan bahwa perawat yang memiliki perilaku caring sebanyak $74,8 \%$ dan perawat yang memiliki perilaku tidak caring sebanyak 25,2\%. Hasil analisis kuesioner menunjukkan bahwa masih adanya perawat yang berperilaku tidak caring yaitu dalam aspek spiritual dan aspek humanis. Aspek spiritual seperti halnya perawat tidak memberikan semangat dan memberikan motivasi agar pasien tidak putus asa terhadap penyakitnya, perawat juga tidak mengingatkan untuk bersabar, tetap melaksanakan sholat dalam keadaan sakit dan berdoa. Perawat yang memiliki perilaku caring yang baik meliputi perilaku pada aspek pemenuhan kebutuhan dasar manusia. Salah satu contoh adalah perawat responsif untuk mengganti cairan infus yang habis,perawat juga responsif memperbaiki infuse line yang macet. Hasil penelitian ini sejalan dengan penelitian yang dilakukan Rini (2015) mendapatkan hasil bahwa sebagian besar perawat memiliki perilaku caring.

Danrlington, et al (2011), semua perawat mampu berperilaku caring dalam memberikan pelayanan keperawatan maka akan terjalin hubungan interpersonal yang baik antara perawat dengan pasien, perawat dengan tenaga kesehatan lainnya, sehingga akan tercapai pelayanan keperawatan yang baik dan berkualitas. Pelayanan yang berkualitas dapat diwujudkan melalui pemberian asuhan keperawatan dengan didasari oleh perilaku caring perawat.

Penelitian ini mendapatkan hasil bahwa pasien yang merasa puas sebanyak 99 pasien $(80,5 \%)$ dan pasien yang merasa tidak puas sebanyak 24 pasien $(19,5 \%)$. Hasil 
pengisian kuesioner responden didapatkan bahwa pasien yang merasa tidak puas karena ruang perawatan yang kurang bersih, tempat tidur yang kurang nyaman dan biaya yang dipungut rumah sakit tidak sesuai dengan pelayanan yang diterima oleh pasien pada saat di rawat di ruang perawatan, sedangkan pasien merasa puas, karena ruang perawat memiliki peralatan medis yang lengkap, perawat menanggapi keluhan pasien dengan cepat, perawat juga dapat memberikan asuhan keperawatan dengan tepat. Penelitian ini sejalan dengan penelitian yang dilakukan oleh Yasmini (2015) mendapatkan hasil bahwa pasien merasa puas sebagian besar pasien merasa puas yaitu sebesar $56,1 \%$ dan sisanya tidak puas.

\section{Hubungan perilaku caring perawat dengan kepuasan pasien di rumah sakit}

Hasil penelitian didapatkan hasil bahwa pada pasien yang merasa puas menunjukkan perawat caring sebesar 84,8\% lebih besar dibandingkan yang tidak caring sebesar 67,7\%, hal tersebut menunjukkan adanya kecenderungan bahwa semakin perawat caring maka pasien akan semakin puas dengan pelayanan kesehatan yang diberikan. Berdasarkan hasil analisis dengan menggunakan uji rank spearman yang dilakukan mengenai hubungan perilaku caring perawat dengan kepuasan pasien diperoleh nilai $\rho$ value sebesar 0,039 yang berarti ada hubungan yang signifikan perilaku caring perawat dengan kepuasan pasien di rumah sakit, terdapat kekuatan hubungan yang rendah dengan nilai $r$ sebesar 0,187.

Sejalan dengan penelitian Ika (2015) dengan hasil perilaku caring perawat kategori baik $(74,6 \%)$, cukup $(46,4 \%)$ dan kepuasan pasien kategori puas (56,3\%), cukup puas $(43,7 \%)$ dengan hasil $p$ value 0,004, sehingga ada hubungan antara perilaku caring perawat terhadap kepuasan pasien. (Isnawati, 2009) menyebutkan bahwa perilaku caring perawat dengan kepuasan pasien sangat erat hubungannya, karena perilaku perawat sebagai provider dimana pelayanan perawat harus dapat dirasakan dan memberi dampak yang positif terhadap pasien sebagai customer (pelanggan) pelayanan kesehatan, dengan demikian, kepuasan pasien merupakan salah satu tujuan pelayanan kesehatan yang diberikan oleh rumah sakit.

\section{KESIMPULAN DAN SARAN}

\section{KESIMPULAN}

Sebagian besar perawat memiliki perilaku caring yang baik. Mayoritas pasien yang di rawat merasa puas dengan pelayanan yang diterima . Ada hubungan yang 
signifikan antara perilaku caring perawat dengan kepuasan pasien di rumah sakit dengan hubungan yang positif, kekuatan hubungan yang sangat lemah dan arah korelasi searah.

\section{SARAN}

Hasil penelitian ini dapat menjadi masukan bagi pihak manajemen RS dan dijadikan acuan bagi bagian penjaminan mutu rumah sakit untuk terus melakukan pemantauan dan evaluasi terkait tingkat kepuasan pasien terutama dalam hal untuk mempertahankan dan meningkatkan perilaku caring perawat agar dapat memberikan kepuasan pada pasien. Pihak rumah sakit juga dapat memberikan kuesioner kepada pasien pulang untuk menilai pelayanan keperawatan dan menilai seberapa puas pasien selama di rawat di rumah sakit. Diharapkan untuk mengupayakan peningkatan perilaku caring perawat dengan pendekatan individu yaitu dengan cara peningkatan pengetahuan dan keterampilan caring melalui pelatihan, seminar, workshop maupun melalui pendidikan formal keperawatan, dapat juga dengan menggunakan pendekatan psikologis yaitu melalui supervisi dan pembinaan serta role model yang baik dari atasan dalam berperilaku caring. Perawat dapat menerapkan 5 aspek untuk meningkatkan kepuasan pasien yaitu cepat, tepat, aman, ramah tamah, dan nyaman, kemudian menerapkan juga $5 \mathrm{~S}$ yaitu senyum, sapa, salam, sopan dan santun agar tercipta caring perawat dengan pasien . Peneliti selanjutnya dapat menambahkan metode observasi sekaligus wawancara mendalam untuk memperoleh hasil penelitian yang lebih baik mengenai perilaku caring yang berhubungan dengan kepuasan pasien

\section{DAFTAR PUSTAKA}

Darlington, D, S. M.B \& Abreu P (2011). Nurse Caring Behaviour As Perceived By Paediatric Patients, Paediatruc Nurses, Paediatric / Caretakers and Physician

Isnawati, Y. (2009). Hubungan Perilaku Caring Perawat dengan Tingkat Kepuasan Pasien Rawat Inap di Puskesmas Melati II Sleman Yogyakarta. Skripsi. Program Studi Ilmu Kesehatan Aisyiyah. Yogyakarta 
Mahardi, Dedi. 2013. The Power Of Care. Jakarta : PT Elex Media Komputindo

Munawaroh. Siti. (2011). Analisis Hubungan Karakteristik dan Kepuasan Pasien dengan Loyalitas Pasien di RSUD Dr. Sutomo Ponorogo. Skripsi. Program Sarjana Fakultas Ilmu Keperawatan Universitas Muhammadiyah. Ponorogo : Tidak dipublikasikan

Notoatmodjo, S. 2012. Metodologi Penelitian Kesehatan. Jakarta: PT. Rineka Cipta.

Nursalam. 2014. Manajemen Keperawatan : Aplikasi dalam Praktek Keperawatan Profesional Edisi 3. Jakarta : Salemba Medika

Rini. 2015. Hubungan Sikap Caring Perawat Terhadap Pelaksanaan Oral Hygiene di Ruang Intensive RSUD Di Moewardi. Surakarta

Supriatin, E. 2009. Tesis : Hubungan Faktor Individu Dan Faktor Organisasi Dengan Perilaku Caring Perawat Di Instalasi Rawat Inap RSUD Kota Bandung. Program Pasca Sarjana, Fakultas Ilmu Keperawatan, Universitas Inonesia

Wike Diah Anjaryani, 2009. Kepuasan Pasien Rawat Inap Terhadap Pelayanan Perawat di RSUD Tugurejo. Tesis. Program Pasca Sarjana Promosi Kesehatan Sumber Daya Manusia. Universitas Diponegoro. Semarang : Tidak dipublikasikan

Yasmini. 2015. Hubungan Caring Perawat Pelaksana Dengan Kepuasan Pasien Di Ruang Rawat Inap SMC Rumah Sakit Telogorejo. Semarang 